Green innovations and organizational change: making better use of environmental technology

Hanna Hottenrott, Sascha Rexhäuser and Reinhilde Veugelers

DEPARTMENT OF MANAGERIAL ECONOMICS, STRATEGY AND INNOVATION (MSI) 


\title{
GREEN INNOVATIONS AND ORGANIZATIONAL CHANGE: MAKING BETTER USE OF ENVIRONMENTAL TECHNOLOGY*
}

\author{
Hanna Hottenrott ${ }^{\dagger}$ Sascha Rexhäuser ${ }^{\ddagger}$, and Reinhilde Veugelers ${ }^{\S}$
}

\begin{abstract}
The literature on within-firm organizational change and productivity suggests that firms can make more efficient use of certain technologies if complementary forms of organization are adopted. This issue may be of even greater importance for the case of greenhouse gas (GHG) abatement technologies imposed by public authority as to reduce social costs of climate change while they are not necessarily expected to increase private returns. Previous research, however, has largely neglected this aspect. Using German firm-level data, we find that organizational change increases the returns to the use of $\mathrm{CO}_{2}$ reducing technologies and that joint adoption leads to higher productivity. Without having introduced complementary organizational innovations, the adoption of $\mathrm{CO}_{2}$ reducing technologies is associated with lower productivity.
\end{abstract}

KEYWORDS - Firm behavior, technical change, innovation, environmental innovation, organizational change, productivity

JEL CODES - D23, O33, O32, Q55, L23, D24

PAPER HISTORY — This version: July 2012

*The author expresses their thank to Martin Achtnicht, Dirk Czarnitzki, Carolyn Fischer, and Michael Schymura as well as the participants in the session Competitiveness and Trade III at the $19^{\text {th }}$ annual conference of the European Association of Environmental and Resource Economists (EAERE) in Prague, Czech Republic, for very helpful comments. This research was done within the framework of the research program "Strengthening Efficiency and Competitiveness in the European Knowledge Economies" (SEEK). We gratefully acknowledge funding from the government of Baden-Württemberg. Hottenrott is thankful for research funding from the Flemish Science Foundation (FWO).

${ }^{\dagger}$ Katholieke Universiteit Leuven (K.U. Leuven), Namsestraat 69, 3000 Leuven, Belgium and Centre for European Economic Research (ZEW), L7,1, 68161 Mannheim, Germany. E-mail: hanna.hottenrott@econ.kuleuven.be

${ }^{\ddagger}$ Centre for European Economic Research (ZEW), L7,1, 68161 Mannheim, Germany and Katholieke Universiteit Leuven (K.U. Leuven), Namsestraat 69, 3000 Leuven, Belgium. E-mail: rexhaeuser@zew.de

${ }^{\S}$ Katholieke Universiteit Leuven (K.U. Leuven), Namsestraat 69, 3000 Leuven, Belgium, and Bruegel, Rue de la Charité 33-1210 Brussels, Belgium. E-mail: reinhilde.veugelers@econ.kuleuven.be 


\section{INTRODUCTION}

The literature on internal firm-organization has emphasized the importance of organizational structures for efficient technology use. Caroli and Van Reenen (2001, p. 1450) make this point more explicitly by saying that "Without the organizational and skill infrastructure, technology alone is not enough." This relationship has become known as the so called "productivity paradox". Studies dealing with environmental technology, however, have largely ignored this stream of literature. This research has mainly focused on the role governmental regulation plays for abatement technology adoption and its consequences for firms' productivity and competitiveness. What this literature has not touched is the question of how abatement technologies integrate into the firms production process and what factors determine its efficient adoption.

Only very recently, Bloom, Genakos, Martin and Sadun (2010) find that better managed firms have lower energy intensities and that advanced environmental management is significantly associated with higher productivity. A further study by Martin, Muûls, de Preux and Wagner (2012) also offers evidence in favor of this view. However, both studies do not allow to conclude that environmental management improves the marginal returns to environmental technology adoption meaning that both have complementary effects on productivity.

In this paper, we extent these approaches by adopting a more general view. In particular, we study whether organizational change can help firms to make more efficient use from greenhouse gas (GHG) mitigation (henceforth "green") technologies. This question has received little attention so far although it deserves even more attention if abatement technology provides high environmental and social returns, but less obvious private benefits. If having to introduce $\mathrm{CO}_{2}$ mitigation technologies would hurt firm's private returns, then any complementary effect from introducing organizational change that moves private returns into positive territory, would be good news for the diffusion of green technologies. To understand the underlying mechanisms through which green technology useespecially if introduced to cope with governmental regulation-interacts with the firms' organization of production processes will be important to understand the impact of green technologies on competitiveness. For this purpose, we draw from the literature dealing with organizational change and technology complementarity.

Milgrom and Roberts (1990) provide the theoretical foundation used in later empirical research. Subsequent research-especially dealing with the case of information technology (IT) adoption-provides a considerable body of empirical evidence showing that adequate organizational structures complement technology use and thus allow firms to achieve larger productivity returns from technology adoption. For instance, Bresnahan, Brynjolfsson and Hitt (2002) identify complementarity effects between organizational change and information technology use and product innovation. Most recently Bloom, Sadun and Van Reenen 
(2012), provide empirical evidence that United States' (US) multinational enterprizes located in the United Kingdom (UK) have higher returns from IT use compared to UK domestic firms. The explanation of this phenomenon is that US firms' internal organization allows to make better use of IT, or in other words, the organizational form US firms have adopted is complementary to IT use. Another piece of empirical evidence for complementarity between organizational change and technology use can be found in Ichniowski, Shaw and Prennushi (1997). They find that the use of individual human resource practices complements the use of human resource management system technologies in steel producing plants, i.e. joint adoption is identified to increase steel finishing lines' productivity. We adopt an empirical approach in line with this literature, however, focusing on productivity effects of green technology adoption. We develop an empirical framework exploring whether green technologies jointly adopted with changes in firms' organizational structure allow to make better use of these technologies. Complementarity between both strategies may more than offset productivity losses of adopting green technology alone.

The following section will illustrate how our contribution fits into the literature dealing with environmental technology adoption and firm performance. Section III. starts with a brief introduction to estimating complementarity followed by our estimation strategy. Section IV. describes the German Community Innovation Survey (CIS) data from the 2009 wave that will be used for the empirical analysis. Results will be discussed in section V. before section VI. concludes.

\section{Abatement Technology Adoption and Firm Performance}

Within the last few decades, the effects of environmental technology adoption on firms' competitiveness was a frequently_and at times hotly—debated topic in economic research that has created a considerable body of empirical evidence at the firm-level. However, previous studies focused rather on the role governmental regulation plays for firm performance and for productivity effects of abatement technologies it has stimulated. In this sense, regulation is central since it has been identified as a key driver for environmental technology invention and adoption ${ }^{1}$.

\footnotetext{
${ }^{1}$ For a recent survey of the impact of regulation on the adoption of environmental technologies, see Popp, Newell and Jaffe (2010). For the early literature, the reader is referred to the review of Jaffe, Newell and Stavins (2002). However, the literature deals rather with inventions than with innovation adoption. A very recent study by Johnstone, Hascic and Popp (2010) finds positive evidence for regulation-induced green innovations. They go as far as saying that "In general, policy, rather than prices, appears to be the main driver of innovation in these technologies" (Johnstone et al. 2010, p. 146). However, the study of Snyder, Miller and Stavins (2003) finds no significant evidence for regulation to be a driver of technology adoption in the chlorine manufacturing industry. Another study by Kerr and Newell (2003) provides empirical evidence that market-based regulation offers greater incentives to adopt environmental technology than standard command-and-control regulation. Horbach (2008) provides further evidence from German innovation panel data regarding the drivers of environmental innovations. Using firm-level data from Italy, Antonioli, Mancinelli and Mazzanti (2011) find that human resource management and
} 
An important strand of literature estimates the impact of a specific measure of the regulatory stringency on firm- or sector productivity. This literature emerged in the beginning of the 1980s after the US and other highly industrialized countries introduced regulations of local water and air pollutants (like $\mathrm{SO}_{2}$ ). This literature typically uses data from the US Pollution Abatement Costs Expenditure (PACE) survey to measure regulation. Abatement costs reject both regulatory stringency and the amount of otherwise productive factors allocated to pollution abatement (like capital or labor) to meet regulatory requirements. Inputs allocated to abatement, especially capital goods, embody, of course, an abatement technology or to use this papers wording, green innovations.

As one of the first using the PACE survey data, Gray (1987) reports a negative correlation of pollution abatement operating costs (PAOC) with total factor productivity (TFP) at the sectoral level indicating no productive use of abatement technology. The study of Gray and Shadbegian (2003) provides estimates for PAOC's impact on both TFP and output in a production function estimation (similar to our approach). Their results based on observations for pulp and paper mills do not suggest a productive use of abatement inputs. Conversely, Shadbegian and Gray (2005) find that abatement capital inputs of pulp and paper mills significantly contribute to the production of desired outputs. However, they do not observe such effects for steel mills and oil refineries. For the latter, the study of Berman and Bui (2001) provides evidence in support of regulation induced abatement investment's positive contribution to productivity growth. They find that there was a "substantial" investment into pollution abatement capital by refineries in a region that has been strongly regulated compared to the whole US. In this region, oil refineries' productivity growth is reported to be on average five percentage points higher than the national average of refineries's productivity growth (which was negative in this period) in a ten year period. In other words, Berman and Bui (2001) do not find support for productivity decreasing effects of pollution abatement investments. Boyd and McClelland (1999) construct measures of inefficiencies in paper mills' production process using standard inputs and investment in pollution abatement equipment (also reported in PACE) to reduce pollution. They find that there is a potential for both input and pollution reduction between two and eight percent to produce the same output, or put it another way, there is a potential to increase output and decrease pollution by investing in abatement technologies. However, the authors weaken this statement by saying that abatement capital investment comes at the expense of otherwise productive investments and therefore may lower overall productivity.

Productivity effects of greenhouse gas mitigation technology, however, remains largely untouched by empirical research. Recently, Commins, Lyons, Schiffbauer and Toll (2011) find that energy taxes as well as the European Emission Trading Scheme (EU-ETS) have negative impacts on total factor productivity. This study, 
however, does not relate productivity consequences of climate policy directly to its fundamental sources in the organization of production processes, namely adoption of abatement technology adoption and its interrelations with other endogenous firm-strategies.

In line with the literature dealing with IT (Caroli and Van Reenen (2001) and Bresnahan et al. (2002)), we argue that firms can increase the productivity impacts of GHG abatement technology if complementary organizational structures are adopted. We therefore show that one has to consider firms' internal behavior as to reach conclusions on productivity effects of green technology. Our approach differs from Bloom et al. (2010) and Martin et al. (2012) also in the way we measure green technology. We understand green technology adoption as any technology that reduces $\mathrm{CO}_{2}$ emissions. On the one hand, $\mathrm{CO}_{2}$ reduction can be achieved by using fossil-fuel inputs more efficiently and is therefore also related to energy-efficiency that may positively affect total productivity. On the other hand, improving the efficiency of fossil fuel use requires to install new capital goods that use fossil fuels at a necessary minimum that is smaller than the levels of currently operated capital. Thus, if fossil fuel inputs and capital are used in rather fixed proportions, increasing efficiency implies to replace old capital ${ }^{2}$ and thus to lower productivity due to higher capital compensation. In general, the total exante expected effect of abatement technology adoption on productivity remains ambiguous.

\section{ESTIMATING COMPLEMENTARITY IN FIRM STRATEgieS}

In this section, we review the literature on how complementarity between different types of economic activities can be accounted for. Complementarity between any two economic activities $x$ and $x^{\prime}$ means that doing more of one increases the marginal benefits of doing more of the other. Special attention to measuring complementarity is required when the economic activities are not of continuous nature like, for instance, internal and external R\&D. Athey and Stern (1998) offer an overview on the methodologies used to test for complementarities and point out difficulties in estimation when the adoption variables are dichotomous. The following section will briefly describe the relevance of the measuring issues with respect to the discrete firm strategies, green innovation and organizational change, to be studied in our analysis.

\footnotetext{
${ }^{2}$ Atkeson and Kehoe (1999) for instance show that capital is rather putty-clay meaning in the case of energy use that capital is operated using a rather fixed necessary minimum of energy inputs so that an increase in energy efficiency is only possible in the long run via replacement of capital goods.
} 


\section{III.A How to Test for Complementarities?}

There are, in principle, two ways to test for complementarity between firm strategies. The first one is the adoption approach. In this approach, a significant positive correlation between the adoption of two activities, conditioning on any other factors, is an indicator of complementarity (Arora and Gambardella 1990, Arora 1996). However, this approach is limited in its validity when $x$ and $x^{\prime}$ are not continuously measurable. Thus, estimating a bivariate limited binary choice model and treating the correlation between the two equations as an indicator of complementarity can be criticized because of incoherence problems. More precisely, such an approach fails to separate complementarity from correlation due to unobserved common other determinants among $x$ and $x^{\prime}$ (Miravete and Pernías 2010). The second avenue to test for complementarity is the productivity approach which can be modified for the case of binary activity variables. ${ }^{3}$

The productivity approach accounts for the effects of $x$ and $x^{\prime}$ on an performance indicator, e.g. productivity. If, for instance, the performance indicator is smooth and a twice differentiable function (say $f$ ) of the arguments $x$ and $x^{\prime}$ that are smooth as well, a positive mixed partial derivative of the objective function with respect to the two variables $\left(\partial^{2} f / \partial x \partial x^{\prime}\right)$ indicates complementarity of the objective function's two arguments because increasing the value of one activity increases the returns of doing more of the other. The concept of supermodularity is directly related to complementarity (Milgrom and Roberts 1990). Endogenous firm technology adoption decisions, in case whether to adopt green innovation or organizational change are a discrete choice. But as long as the set of combinations of choice variables is defined over a sublattice (Milgrom and Roberts, 1990, 1995), the concept of supermodularity also works for binary arguments.

The condition saying that increasing the value of one activity increasing the marginal return of the other reads in the binary case as adopting one strategy increases the returns to the other strategy that is already adopted. Moreover, adopting both jointly leads to a higher performance than adopting both in isolation, simply because the one increases the marginal returns of the other. In this

\footnotetext{
${ }^{3}$ Another approach that is pursued at times is one that Athey and Stern (1998) label the "random practise mode", which is roughly speaking a mix of adoption and productivity approach. It is used if the adoption variables are binary and potentially correlated and if no data on an outcome variable is available. Miravete and Pernías (2006) use binary dummy variables and estimate multi-equation discrete choice models with error components for each strategies' unobservable returns and control for unobserved correlation among the different adoption equations. Similar approaches are used in Kretschmer, Miravete and Pernías (2012), Arora, Forman and Yoon (2010), and Gentzkow (2007).
} 
sense, the condition for supermodularity and complementarity reads as follows: ${ }^{4}$

$$
\begin{aligned}
f(x)+f\left(x^{\prime}\right) & \leq f\left(x \vee x^{\prime}\right)+f\left(x \wedge x^{\prime}\right), \text { or: } \\
f(1,0)+f(0,1) & \leq f(1,1)+f(0,0),
\end{aligned}
$$

In the following, we are interested in how this condition-of course for the case of green technology adoption and organizational change—can be adequately tested for.

\section{III.B Empirical Framework and Estimation Strategy}

We now turn to the estimation of the impact of green innovation on firm performance and whether organizational change can help making better use of green technology. If both green innovation and organizational change contribute to better firm performance, we would expect the productivity increase to be even higher if both forms of innovations had been adopted compared to the case in which either green or organizational innovations would have been independently introduced. Although complementarity, as defined by inequality 1 is perfectly symmetric in the two strategies, we are particularly interested whether the adoption of organizational changes improves the marginal returns of introducing green technologies. Particularly, when green innovations alone would decrease firm's productivity, we are interested to see whether additionally introduced organizational change may at least (partially) offset green technology's negative productivity effects. This could hold because such a combined green change event would result in better performing business processes, worker relationships and/or customer or supplier relationships, mitigating any negative productivity effects from having to introduce green technology in isolation.

For the purpose of testing these relationships on our data, we employ the standard procedure to test for difference in firm-level productivity, as for instance used by Gray and Shadbegian (2003) and Shadbegian and Gray (2005) to estimate pollution abatement capital investment's impact on productivity. Let $Y=$ $A \cdot f(K, L, E, M)$ be firms' output depending on capital $(K)$, labor $(L)$, energy $(E)$, and material $(M)$ inputs, where $Y \rightarrow \mathbb{R}^{+}$. Firms that only differ in (total factor) productivity $A$ but use the same amounts of other inputs may differ in the amount of output produced. Green technology adoption, however, means that some of otherwise productive capital inputs are allocated to pollution abatement.

Since the technology choices are defined over the sublattice $\{(0,0),(1,0),(0,1)$, $(1,1)\}$, with $f:\{0,1\}^{2} \rightarrow \mathbb{R}^{+}$, we can test whether organizational change complements the use green technology and-in the end-improves its effects on productivity by testing whether $f$ is supermodular in its arguments. Supermodularity is

\footnotetext{
${ }^{4}$ See Milgrom and Roberts (1990) for a proof and further details as well as Holmstrom and Milgrom (1994).
} 
present if the following condition applies:

$$
\begin{array}{r}
\quad f(1,0 \mid K, L, E, M)+f(0,1 \mid K, L, E, M) \\
\leq f(0,0 \mid K, L, E, M)+f(1,1 \mid K, L, E, M) .
\end{array}
$$

This condition says that if green technology adoption and organizational change are complements, we would observe the productivity returns of joint adoption of both innovations to be larger than the sum of the adoption of either green technology or organizational change alone. Assuming a simple production function of the Cobb-Douglas type, productivity $(A)$ is the sum of the residual $\varepsilon_{i}$ for observation $i$ and the constant term of a regression of logged output on logged inputs, known as the Solow residual (Solow 1957). Thus, productivity is like a "neutral shifter" that increases output holding total input requirements constant (see Syverson (2011) for an overview on the literature on estimating productivity). Of course, we are interested in the productivity consequences of green technology and organizational change and therefore separate these effects from the error term. The resulting estimation equation reads as follows:

$$
\begin{aligned}
y_{i}= & \beta_{0}+\beta_{k} k_{i}+\beta_{l} l_{i}+\beta_{e m} e m_{i} \\
& +\beta_{10} G R E E N \_O N L Y_{i}+\beta_{01} O R G A \_O N L Y_{i}+\beta_{11} B O T H_{i} \\
& +\boldsymbol{\beta}_{c}^{\prime} \boldsymbol{C}+\varepsilon_{i},
\end{aligned}
$$

where lower case letters indicate logarithms. As later discussed in the data section, we have only information on the intermediate inputs as an aggregate, so that $e m_{i}$ measures logged material and energy inputs. The term NEITHER $R_{i}$ is linearly dependent on the other three adoption combinations (GREEN_ONLY, $O R G A_{-} O N L Y, B O T H$ ) and thus offers no further information. In other words, $f(0,0 \mid \bar{K}, L, E M, C)=0$. Any further fixed control variables are included in the vector $C$.

In the productivity approach framework to test for complementarity, we are not in a situation as Mohnen and Röller (2005) where the assumed complementary variables are exogenous to the firms. Instead, firm's decision to adopt green and organizational innovations are endogenous strategy variables. As the error term (plus the constant)—the Solow residual—is likely to reflect productivity, and as the use of abatement technology is likely to affect productivity, as the literature survey in section III. has shown, $\operatorname{cov}\left(G R E E N \_O N L Y, \varepsilon\right) \neq 0$ and $\operatorname{cov}(B O T H, \varepsilon) \neq$ 0 , or in other words, our measures of green technology adoption are endogenous. Organizational change is endogenous too ${ }^{5}$. Moreover, green technology adoption and organizational change are expected not to be independent of each other. If for instance organizational change really improves green technology's productivity and clever managers are aware of this fact, both types of technology adoption

\footnotetext{
${ }^{5}$ See test for endogeneity of these variables below.
} 
would be highly correlated. Unfortunately, managers' abilities are unobservable in our data.

As to take this endogeneity ${ }^{6}$ into account, the output equation (equation (4) is estimated using the two-stage least squares instrumental variable estimator. What makes things complex is that the endogenous regressors are binary indicators for any of the innovation adoption combinations (GREEN_ONLY,ORGA_ONLY, and $B O T H$ ). To cope with this problem, Wooldridge (2002, p. 623) suggests to estimate binary response models for the endogenous dummies including a vector of instruments $(Z)$ and any other variable from equation 4 (denoted by the vector $D$ ). The predicted probabilities from the binary response models can be used as instruments in the two-stage least squares estimation.

We therefore explicitly model a firm's discrete choice to adopt green technology labeled as $X^{g r}$ and organizational change (hereinafter $X^{o r}$ ). The dummy $X^{g r}$ takes the value one if green technology is adopted, irrespectively whether organizational change is adopted or not, representing the aforementioned cases $x$ and $x \wedge x^{\prime}$. As said, we expect the decisions to adopt green technology and organizational change not to be independent. A bivariate response model allows both adoption decisions to depend on each other, where the decision to adopt organizational change $\left(X^{\text {or }}\right)$ is measured in a same similar fashion as green technology. The bivariate discrete response model read as follows:

$$
\begin{aligned}
X_{i}^{g r} & =\alpha_{0}^{g r}+\boldsymbol{\beta}^{\prime g r} \boldsymbol{Z}_{i}^{g r}+\boldsymbol{\gamma}^{\prime g r} \boldsymbol{D}_{i}^{g r}+\varepsilon_{i}^{g r} \\
X_{i}^{o r} & =\alpha_{0}^{o r}+\boldsymbol{\beta}^{\prime o r} \boldsymbol{Z}_{i}^{o r}+\boldsymbol{\gamma}^{\prime o r} \boldsymbol{D}_{i}^{o r}+\varepsilon_{i}^{o r}, \text { where } \\
{\left[\begin{array}{l}
\varepsilon^{g r} \\
\varepsilon^{o r}
\end{array}\right] } & \sim N\left(0,\left[\begin{array}{cc}
\sigma_{g r}^{2} & \sigma_{g r, o r} \\
\sigma_{g r, o r} & \sigma_{o r}^{2}
\end{array}\right]\right)
\end{aligned}
$$

Any other unobservable factors ( $\varepsilon^{g r}$ and $\varepsilon^{o r}$ ) determining adoption choices are assumed to be distributed jointly normally and are allowed to be correlated among the equations. The instruments included in the vector $(Z)$ are discussed at length in the following section. The bivariate probit model has in addition the nice feature that it can report the conditional adoption probabilities for each of the four

\footnotetext{
${ }^{6}$ To see that the innovation decision variables (GREEN_ONLY,ORGA_ONLY, and $B O T H$ ) are really endogenous, a regression-based test is carried out. Wooldridge (2002) argues in favor of this test that was introduced by Hausman (1978) and Hausman (1983). The test requires to regress the endogenous variables on their instruments ( $\operatorname{Prob}\left(\mathrm{X}^{g r}=1, \mathrm{X}^{\text {or }}=0\right.$ ), $\operatorname{Prob}\left(\mathrm{X}^{g r}=0, \mathrm{X}^{o r}=1\right)$, and $\operatorname{Prob}\left(\mathrm{X}^{g r}=1, \mathrm{X}^{o r}=1\right)$, which are discussed in the following $)$ and to use the residuals from this regressions as regressors in the structural equation. If the residuals are significantly different from zero, endogeneity of the innovation adoption variables is presented, which is the case in our model. The three residuals from the regressions of GREEN ONLY, $O R G A \_O N L Y$, and $B O T H$ on the instruments are all significantly different from zero at the 95 percent confidence level in the structural model (equation 4).
} 
possible adoption decision combinations,

$$
\begin{aligned}
& \operatorname{Prob}\left(X^{g r}=0, X^{o r}=0\right)=\operatorname{Prob}\left(x \wedge x^{\prime}\right) \\
& \operatorname{Prob}\left(X^{g r}=1, X^{o r}=0\right) \\
& \operatorname{Prob}\left(X^{g r}=0, X^{o r}=1\right) \\
& \operatorname{Prob}\left(X^{g r}=1, X^{o r}=1\right)
\end{aligned}
$$

that are needed to test for complementarity of the two innovation adoption choices. Of course, for every firm the predicted probabilities for all four cases necessarily sum up to unity. These predicted choice probabilities - that are conditioned on factors determining adoption and the covariance of the two equations' errorsare used as the instruments to for endogenous adoption decision combinations (GREEN_ONLY,ORGA_ONLY, and BOTH) in the output (or productivity) equation (see equation 4).

\section{DATA AND Choice of Instruments}

The German part of the European-wide Community Innovation Survey (CIS) provides the data for our analysis. We draw from the wave collected in 2009 which refers to the period 2006-2008. ${ }^{7}$ The 2009 cross-section offers information on firm-level green technology adoption and organizational innovation in addition to a number of other innovation-related and more general firm characteristics. The target population covers all firms with at least five employees in the German business sector. The German CIS data appears to be particularly suitable to our study since Germany is one of the world's leading inventors, producers and exporters of green technology and has at the same time a long and persistent tradition of environmental regulations. In this sense, the 2009 cross-section provides a unique set of variables that account for the adoption of environmental technology and organization change also including factors that affect the respective technology adoption to construct control variables. We supplement the survey data with information on patent applications of firms in our sample filed at the European Patent Office (EPO) in the period 1978-2009 in order to construct a control measure for the firm technology stock. Moreover, sectoral market concentration measures are merged with the firm-level data at firms' sector affiliation at the NACE (Nomenclature statistique des Activités économiques dans la Communauté Européenne) 3-digit level. This data comes from the German Monopoly Commission. The present study focuses on information of 3,896 firms' observations after the deletion of observations from the original data-set due to item non-response

\footnotetext{
${ }^{7}$ The survey is conducted annually by the Centre for European Economic Research (ZEW), infas Institut fuer Sozialforschung and ISI Fraunhofer Institute on behalf of the German Federal Ministry of Education and Research. A detailed description of the survey data and the sampling method can be found in the background reports available at ZEW.
} 
or outlier correction. ${ }^{8}$

\section{IV.A Constructing Instruments: A Discrete Response Model of Innovation Choices}

As described in the previous section, in the first stage of our econometric approach we estimate a bivariate probit model on the likelihood for introducing green and organizational innovations. Thus, the dependent variables at this stage are the adoption decisions obtained from the survey for green and organizational innovations.

Green innovation adoption is defined as the firms' carbon dioxide abatement technology adoption. The German CIS questionnaire measures this variable in an ordinal scale from innovation adoption with no, low, medium, and large effects on $\mathrm{CO}_{2}$ mitigation. In the following, the green innovation dummy takes the value one if at least innovation with a small impact on $\mathrm{CO}_{2}$ reduction had been achieved and takes the value zero otherwise ${ }^{9}$.

Organizational change comprises a variety of activities in our study. These can be categorized in three areas. First, the introduction of new methods of process organization such as quality management, supply chain management, lean production, and knowledge management. Second, the introduction of new forms of work management including decentralization, job rotation, teamwork, and the structure of teams and departments. Third, we consider activities like new methods of dealing with external relations, the engagement in alliances and cooperations with other firms, customers or suppliers as well as marketing innovations as forms of organizational change. If firms introduced at least one of these three forms of organizational change, we set our variable indicating organization change to one and to zero otherwise. This results in two binary response variables $\left(X^{g r}, X^{o r}\right)$ to be used as dependent variables in the bivariate probit estimation of green and organizational innovation adoption on several controls. This model then yields the predicted probabilities for every combination $\{(1,0),(0,1),(0,0),(1,1)\}$ of these two variables. These predicted values are subsequently used as instruments in the productivity equation.

We assume the conditional predicted probabilities for green innovation and organizational change to depend on a number of factors that determine the decision to adopt one or the other.

For environmental technology adoption the literature has identified governmental regulation as a key driver. We therefore construct a dummy variable $(R E G)$ that takes the value one if the firm indicated in the survey that environ-

\footnotetext{
${ }^{8}$ The sample distribution across industries is presented in Table A.1 in the Appendix.

${ }^{9}$ Regarding the definition of the green innovation dummy, sensitivity analyses are performed. A more strict definition, meaning that the dummy takes the value of one if the environmental impact is at least medium, leaves estimation coefficients and statistically significance rather unchanged. If, however, the dummy takes the value of one only in cases when firms reported a high environmental impact, the results change in a way that complementarity becomes even stronger and green innovation introduced alone has an even more negative impact on productivity.
} 
mental regulation (including taxes) had induced the introduction of some form of innovation with beneficial effects for environment. This variable is also included in the organizational innovation equation as environmental regulations may not only trigger green innovations, but also induce firms to adapt their organizational structures. If there are no direct effects from environmental regulation on organizational innovation adoption to be expected, i.e. it operates like an exclusion restriction, finding a significant positive effect could be interpreted as positive evidence for complementarity, see Athey and Stern (1998).

Besides regulation, firm-level characteristics may have a decisive impact on whether or not a certain type of innovation is being introduced. Capital-intensive production may use more energy inputs and thus emit more pollutants. In the presence of regulation or relatively expensive energy inputs, firms operating more capital could be more likely to adopt environmental technology. We therefore control for logged capital inputs $\left(\log _{-} C A P\right)$. The same applies to firms with higher energy- and material inputs ( $\left.\log _{-} E N M A T\right)$. Additionally, larger firms may be more likely to innovate. Hence, we also control for firm size by including the logged number of employees $\left(\log _{-} L A B\right)$. Moreover, we want to account for the firm's age $(A G E)$ as their age may affect the propensity to innovate. We further control for competitive forces using firms' binary response to the question whether they perceived competition to be hard or not (HARDCOMP) as well as the Herfindahl-Index of sales concentration $(H H I)$ as a more objective measure of industry concentration. On the one hand, firms could be expected to refrain from introducing green technology in the presence of hard competition, in order not to risk productivity losses that reduce their competitiveness. On the other hand, competitive pressure may force firms to gain a competitive edge by being innovative. Thus, firms may see a need to implement organizational change to better exploit existing production technologies. In line with this paper's central hypothesis, the latter effect may also induce green technology, so that we expect competitive pressure to influence both technology choices in the same direction.

From the labor and firm organization literature we derive important determinants for the adoption of technological and organizational change alike. Caroli and Van Reenen (2001) point to the fact that organizational change needs particularly skilled labor as to cope with more complex structures in the work flow. We address this by including two different variables: The share of graduated employees in total workforce (HIGHSKILL) and the firms' expenditure on training per employee ( $E D U C_{-} P E M P$ ). The former controls for firms' general propensity to adopt organizational change while the latter explicitly addresses technology adopters' need for skilled workforce as the productivity paradox predicts. This means that firms that have adopted any kind of technical innovation need skilled personnel to operate capital that embodies the new technology. Caroli and Van Reenen (2001) show that organizational change and the skill level of employees are complementary. The obvious consequence of this finding, of course, is 
that the level of human capital itself is an important determinant of whether organizational change within the firm can happen. In other words, they invest in new human capital that adds to their current stock of human capital ${ }^{10}$. Likewise, it is crucial to control for the firms' general innovative capabilities. As a first measure, firms research an development expenditures scaled by the number of employees $\left(R \& D_{-} I N T\right)$ is considered. However, this measures reflects rather the costs of R\&D and not necessarily its innovation capacity. Hence, we include dummies for the case that the firm had successfully introduced product $\left(P D_{-} I N N O\right)$ or process innovations $\left(P_{-} I N N O\right)$ before. For further robustness checks, the variable INNOVATOR takes the value of one if at least one type of innovation (product and process) was introduced and zero otherwise. As a further measure for technological advance, the effects from the firms' stock of technological knowledge is captured by including the patent stock ( $P A T S T O C K$ ). It was constructed using the perpetual inventory method, where a yearly depreciation rate of the knowledge stock of 15 per cent was assumed ${ }^{11}$.

Finally, we control for whether the firm is located in Eastern Germany ( $E A S T_{-}$ $G E R)$ as structural differences between the West and East German federal states persist since the reunification. ${ }^{12}$

Descriptive statistics of the variables and their timing are summarized in Table A.2 in the Appendix. The results from this bivariate probit model are presented in Tables 2 and 3 and will be discussed in subsection 4 .

\section{IV.B Correlations Between Adoption Decisions}

The descriptive analysis of adoption decision frequencies (Table 1) clearly show an important point in the analysis of complementarity between discrete firm strategies. It is clear to see that organizational change jointly adopted with green technology appears more frequently in our sample than the case that green technology is adopted only. In other words, the adoption decisions do not seem to be randomly allocated in the sample which indicates that there is an underlying correlation among the strategies. This correlation becomes more obvious if we

\footnotetext{
${ }^{10}$ This is in line with the literature that predicts technical change and organizational change complementarity to be skill-biased (Bresnahan et al. 2002). However, Goldin and Katz (1998) demonstrate that technical change is not necessarily biased towards more skilled labor. The transition from human-capital or skill-intensive handicraft manufacturing before the industrial revolution towards factor or assembly-line production was characterized by an increase in the relative need of skilled labor. In contrast, the transition from factory manufacturing towards more flexible modern forms of manufacturing appears to be skill-biased. This finding also seems to support the link between organizational and technical change that is, however, not explicitly touched by Goldin and Katz (1998).

${ }^{11}$ Typically scholars have measured the technology knowledge stock of firms by the discounted sum of prior R\&D investments and/or their patent stock (see e.g. Bloom and Van Reenen (2002)). We use a 15\% depreciation rate as suggested by Griliches and Mairesse (1984).

${ }^{12}$ We distinguish 22 different sectors based on aggregated 2-digit NACE-levels which is the official classification of economic activities in the European Community. See Table A.1 in the appendix.
} 
look at the expected frequency reported in parentheses that reflect the estimated frequency that would have been observed, had the two adoption decisions been independent. The expected frequency for adoption of green technology only is larger than the one for joint adoption. This correlation could be interpreted as good news for finding complementarity, but needs to be singled out from other non-random factors determining this correlation.

In order to address this problem of non-randomly assigned adoption decisions, we will use the two stage procedure as described before where we first estimate a bivariate discrete choice model that allows for correlation among the adoption equations. The predicted probabilities for each of the adoption combinations to appear in the sample are used as instruments in a second stage estimation.

Table 1: Adoption Decision Frequencies and Relative Frequencies

\begin{tabular}{|c|c|c|c|c|c|c|c|}
\hline \multirow[b]{2}{*}{$X^{g r}$} & \multicolumn{2}{|c|}{$X^{o r}$} & \multirow[b]{2}{*}{ TotaL } & \multirow[b]{2}{*}{$X^{g r}$} & \multicolumn{2}{|c|}{$X^{o r}$} & \multirow[b]{2}{*}{ ToTAL } \\
\hline & 0 & 1 & & & 0 & 1 & \\
\hline 0 & $\begin{array}{c}1,624 \\
(1,443.4)\end{array}$ & $\begin{array}{c}1,094 \\
(1,274.6)\end{array}$ & 2,718 & 0 & $\begin{array}{c}41.68 \% \\
(37.05 \%)\end{array}$ & $\begin{array}{c}28.09 \% \\
(32.72 \%)\end{array}$ & $69.77 \%$ \\
\hline 1 & $\begin{array}{c}445 \\
(625.6)\end{array}$ & $\begin{array}{c}733 \\
(552.4)\end{array}$ & 1,178 & 1 & $\begin{array}{c}11.42 \% \\
(16.05 \%)\end{array}$ & $\begin{array}{c}18.81 \% \\
(14.18 \%)\end{array}$ & $30.23 \%$ \\
\hline TOTAL & 2,069 & 1,827 & 3,896 & TотAL & $53.10 \%$ & $46.90 \%$ & $100.00 \%$ \\
\hline \multicolumn{8}{|c|}{$\begin{array}{l}\text { Expected frequencies appear in parentheses. } \\
\text { Pearson } \text { chi }^{2}(1)=159.3419 \mathrm{Pr}=0.000 \\
\text { Kendall's tau-b }=0.2022, \mathrm{P}>\mathrm{z}=0.0000\end{array}$} \\
\hline
\end{tabular}

\section{RESULTS}

Before discussing the results for the test of complementarity, we first look at the bivariate discrete response model for firms' choice of adopting green and organizational innovations. The predicted probabilities from this model serve as instruments in the output equation (Wooldridge 2002, p. 623).

\section{V.A Results from the Bivariate Probit Model}

The results from the bivariate probit model appear in Table 2. The most relevant information from this table is the correlation among the two equations, which is significantly positive. Whether this correlation is due to complementarity or just because of unobserved correlation is unclear at this stage of the analysis as argued by Miravete and Pernías (2010). The coefficients of the included variables show, by and large, the expected signs. ${ }^{13}$ The regulation variable is significantly affecting

\footnotetext{
${ }^{13}$ The share of highly qualified personnel, however, has a negative effect on the green innovation, possibly reflecting the capital intensity of firms most introducing such innovations (see also the positive effect of logged capital on $X^{g r}$ ). Training expenses, on the other hand, have a positive
} 
the adoption of green innovations, but also of organizational innovations. If regulations are seen from an exclusion restriction perspective, with no direct effect on organizational innovations, the positive significant coefficient can be interpreted as evidence of complementarity, i.e. driven by the higher returns on organizational innovations when combined with environmental innovations.

We turn to the marginal effects for each combination of the dependent variables as presented in Table 3. The marginal effects (at means, and for dummies as discrete changes from 0 to 1 ) are reported for model specification IV only. While these results, of course, also do not allow to conclude that complementarity is present, it offers interesting insights on why a respective choice of innovation adoption is done by firms. We see from the marginal effects on the likelihood to introduce GREEN_ONLY is indeed significantly driven by regulatory forces. However, the effect on introducing $B O T H$, i.e. also organizational change, is much larger. Regulation affects significantly negatively the likelihood of adopting only organizational innovations. The overall positive effect in the bivariate probit results for organizational innovations therefore come from the combined case. In line with predictions from the literature on skill-biased organizational change, we find the share of highly qualified employees to positively affect the realization of organizational change. Interestingly, training of employees is of even greater importance than their initial skill level. While we find a negative correlation between HIGHSKILL and the introduction of green innovations, probably due to the more capital intensive production of firms that have the potential to introduce $\mathrm{CO}_{2}$ emitting technologies, we find a strong positive effect of the firms' expenditures on the training of their employees ( $E D U C_{-} P E M P$ ) on the joint introduction of both green innovations and organizational change (Bresnahan et al. 2002). In general, firms combining green and organizational innovations are typically more endowed with innovation capacities than firms exclusively introducing green innovations.

effect in both equations. Firm size is positive for both strategies. General innovative capabilities as measured by the past innovations dummies are positive and highly significant for both forms of innovations. As expected, older firms are less likely to change their organizational structures. Firms in Eastern Germany are less likely to introduce green innovations. The Herfindahl-Index is positive in the organizational change equation, but insignificant for green innovations. Firms reporting to face tough competitive pressure are more likely to introduce green innovations. However, no causal relationship can be claimed at this point. Industry dummies are jointly significant in both equations capturing effects from different technological environments and industry-level life cycle effects. 


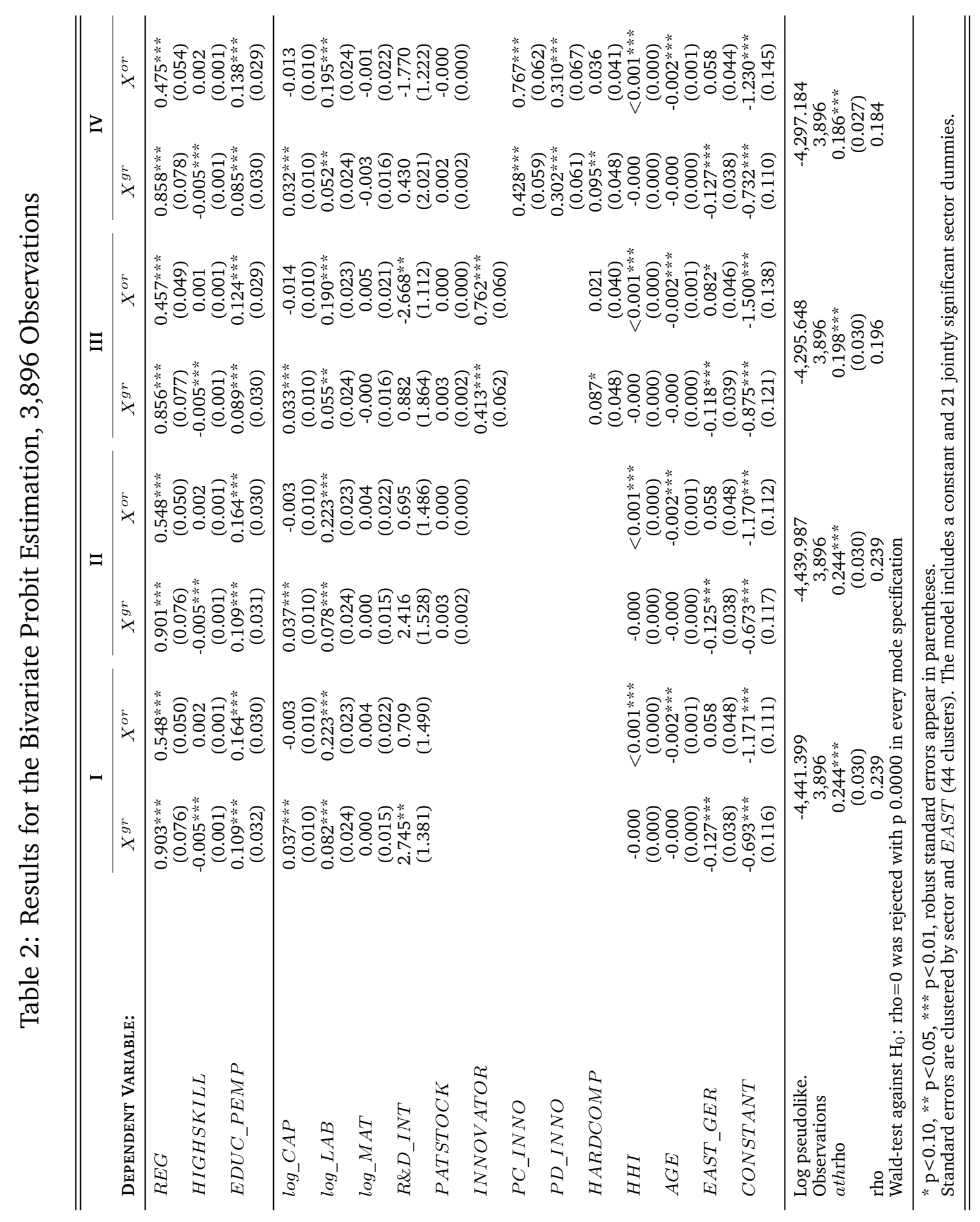


The measure of sales concentration $(H H I)$ though shows that higher industry concentration, i.e. weaker competition, reduces the likelihood to innovate green, but had a positive effect on organizational innovations. The control variables for capital and labor show the expected signs. More capital intensive firms are more likely to innovate green and more likely to adopt organizational jointly with green innovation. Larger firms in terms of employees, on the other hand, are less likely to innovate green only, but have a larger likelihood of innovating their organizational structures and to do so jointly with reducing their $\mathrm{CO}_{2}$ emissions. Older firms are less inclined to change their organizational characteristics and are also more likely to have introduced neither organizational nor environmental innovations. Eastern German firms are more likely to change their organization compared to firms in the Western states, but tend to pure organizational changes without simultaneously adopting green innovations.

Table 3: Marginal Effects for any Adoption Decision Combination from the Bivariate Probit Estimation, Specification IV only

\begin{tabular}{|c|c|c|c|c|}
\hline DEPENDENT VARIABLE: & NeIther & GREEN ONLY & ORGA. ONLY & Вотн \\
\hline$R E G$ & $\begin{array}{c}-0.261 * * * \\
(0.020)\end{array}$ & $\begin{array}{c}0.073 * * * \\
(0.012)\end{array}$ & $\begin{array}{c}-0.050 * * * \\
(0.017)\end{array}$ & $\begin{array}{c}0.238 * * * \\
(0.022)\end{array}$ \\
\hline$H I G H S K I L L$ & $\begin{array}{c}0.000 \\
(0.000)\end{array}$ & $\begin{array}{c}-0.001^{* * * *} \\
(0.000)\end{array}$ & $\begin{array}{c}0.001 * * * \\
(0.000)\end{array}$ & $\begin{array}{c}-0.001^{* * *} \\
(0.000)\end{array}$ \\
\hline$E D U C_{-} P E M P$ & $\begin{array}{c}-0.053^{* * * *} \\
(0.009)\end{array}$ & $\begin{array}{c}-0.001 \\
(0.006) \\
\end{array}$ & $\begin{array}{l}0.025^{* * *} \\
(0.010)\end{array}$ & $\begin{array}{c}0.030 * \cdots * \\
(0.006)\end{array}$ \\
\hline $\log _{-} C A P$ & $\begin{array}{c}-0.002 \\
(0.003)\end{array}$ & $\begin{array}{c}0.007 * * * \\
(0.002)\end{array}$ & $\begin{array}{l}-0.009 * * \\
(0.003)\end{array}$ & $\begin{array}{l}0.004 * * \\
(0.002)\end{array}$ \\
\hline $\log \__{-} L A B$ & $\begin{array}{c}-0.065 * \cdots * * \\
(0.008)\end{array}$ & $\begin{array}{c}-0.013 * * * * \\
(0.004)\end{array}$ & $\begin{array}{c}0.047 * * * \\
(0.007)\end{array}$ & $\begin{array}{c}0.030 * * * * \\
(0.005)\end{array}$ \\
\hline $\log \__{E} N M A T$ & $\begin{array}{c}0.001 \\
(0.006)\end{array}$ & $\begin{array}{l}-0.000 \\
(0.004)\end{array}$ & $\begin{array}{c}0.000 \\
(0.007)\end{array}$ & $\begin{array}{c}-0.000 \\
(0.003)\end{array}$ \\
\hline$R \& D \_I N T$ & $\begin{array}{c}0.440 \\
(0.383)\end{array}$ & $\begin{array}{c}0.264 \\
(0.395)\end{array}$ & $\begin{array}{c}-0.584 \\
(0.578)\end{array}$ & $\begin{array}{c}-0.120 \\
(0.325)\end{array}$ \\
\hline PATSTOCK & $\begin{array}{c}-0.000 \\
(0.000)\end{array}$ & $\begin{array}{c}0.000 \\
(0.000)\end{array}$ & $\begin{array}{c}-0.000 \\
(0.000)\end{array}$ & $\begin{array}{c}0.000 \\
(0.000)\end{array}$ \\
\hline PC_INNO & $\begin{array}{c}-0.265 * * * \\
(0.016)\end{array}$ & $\begin{array}{c}-0.030 * * * * \\
(0.010)\end{array}$ & $\begin{array}{c}0.113^{* * * *} \\
(0.021)\end{array}$ & $\begin{array}{c}0.182^{* * * *} \\
(0.016)\end{array}$ \\
\hline PD_INNO & $\begin{array}{c}-0.134 * * * \\
(0.022)\end{array}$ & $\begin{array}{c}0.010 \\
(0.010)\end{array}$ & $\begin{array}{c}0.028 \\
(0.018)\end{array}$ & $\begin{array}{l}0.096 * * * * \\
(0.0180)\end{array}$ \\
\hline$H A R D C O M P$ & $\begin{array}{l}-0.026^{*} \\
(0.016)\end{array}$ & $\begin{array}{c}0.011 \\
(0.008)\end{array}$ & $\begin{array}{l}-0.006 \\
(0.013)\end{array}$ & $\begin{array}{l}0.020 * * \\
(0.010)\end{array}$ \\
\hline$H H I$ & $\begin{array}{c}-0.000 \\
(0.000)\end{array}$ & $\begin{array}{c}<-0.001^{* *} \\
(0.000)\end{array}$ & $\begin{array}{c}<0.001^{* * *} \\
(0.000)\end{array}$ & $\begin{array}{c}0.000 \\
(0.000)\end{array}$ \\
\hline$A G E$ & $\begin{array}{c}0.001 * * * \\
(0.000)\end{array}$ & $\begin{array}{l}<0.001^{*} \\
(0.000)\end{array}$ & $\begin{array}{c}-0.001^{* * * *} \\
(0.000)\end{array}$ & $\begin{array}{c}<-0.000 * * * \\
\quad(0.000)\end{array}$ \\
\hline$E A S T \_G E R$ & $\begin{array}{c}0.003 \\
(0.015) \\
\end{array}$ & $\begin{array}{c}-0.026^{* * * *} \\
(0.007)\end{array}$ & $\begin{array}{c}0.039^{* * * * *} \\
(0.014)\end{array}$ & $\begin{array}{l}-0.016 * \\
(0.008) \\
\end{array}$ \\
\hline Case Probabilities & $\begin{array}{c}\operatorname{Pr}\left(\mathrm{X}^{g r}=0\right. \\
\left.\mathrm{X}^{o r}=0\right) \\
0.4071\end{array}$ & $\begin{array}{c}\operatorname{Pr}\left(\mathrm{X}^{g r}=1\right. \\
\left.\mathrm{X}^{\text {or }}=0\right) \\
0.1207\end{array}$ & $\begin{array}{c}\operatorname{Pr}\left(\mathrm{X}^{g r}=0\right. \\
\left.\mathrm{X}^{o r}=1\right) \\
0.3177\end{array}$ & $\begin{array}{c}\operatorname{Pr}\left(\mathrm{X}^{g r}=1\right. \\
\left.\mathrm{X}^{o r}=1\right) \\
0.1545\end{array}$ \\
\hline
\end{tabular}

From the bivariate probit regression, we use the predicted values for the conditional probabilities for any combination of the two innovation variables (See 
bottom of Table 3) as instruments in the output equation. A result worth being mentioned here is that the case probability for observing the outcome BOTHconditioned on several factors and most importantly the covariances of the two equations' error terms-is smaller than the one directly observed in the sample (18.81\%). This finding can be interpreted in a way that unobserved correlation among the adoption decisions has been—at least partly-corrected for by estimating both equations jointly.

\section{V.B Estimating Productivity Effects of Green Innovation and Organizational Change}

For the following step in which we estimate conditional productivity effects of the adoption decisions, we chose the category "Neither" as the reference category, so that in the second stage regressions, $f(0,0)$ is set to zero. After all other factors have been controlled for, the test for complementarity then reduces to:

$$
\begin{aligned}
f(1,0)+f(0,1)-f(1,1) & \leq 0, \text { or } \\
f\left(G R E E N \_O N L Y\right)+f\left(O R G A \_O N L Y\right)-f(B O T H) & \leq 0,
\end{aligned}
$$

which means that we are interested in the effect of the innovation adoption decisions on the respective measure for productivity after all other factors determining productivity have been taken into account. When using the term productivity we simply mean the difference in produced output given constant inputs of capital $\left(\log _{-} C A P\right)$, labor $\left(\log _{-} L A B\right)$, and energy and materials $\left(\log _{-} M A T\right)$. Since the innovation adoption decisions are expected to be endogenous, their predicted values from the bivariate probit model serve as instruments in a two-stage least squares estimation procedure. The results from the second stage regression are presented in Table 4 below.

The results indicate that when controlling for factor inputs such as capital, labor, materials including energy and general innovation capabilities, we find considerable differences in the productivity effects of the adoption decision for green and organizational innovations. As expected and as suggested by many critiques of environmental regulations and policy-induced green innovations, we find a strong negative effect from carbon dioxide abatement technology adoption if it had been introduced solely (GREEN_ONLY). Holding all other inputs fixed, a firm that has adopted green technology alone faces significant losses in productivity (-1.484 percent in our preferred model specification IV). Organizational change (ORGA_ONLY), however, is associated with significant positive effects on output holding all inputs fixed. Importantly, however, those firms that adopted green technologies jointly with organizational change do experience a productivity increase since they can produce 0.664 percent more output with the same amounts of inputs compared to firms that do neither. The coefficient of $B O T H$ is positive and statistically significant pointing to a complementary relationship between green innovations and organizational change. 
Table 4: Estimation results of the output equation

\begin{tabular}{|c|c|c|c|c|}
\hline \multirow[b]{2}{*}{ DEPENDENT VARIABLE: } & \multicolumn{4}{|c|}{ IV-REGRESSIONS ${ }^{\dagger}$} \\
\hline & $\begin{array}{c}\text { LOG(OUTPUT) } \\
\text { I }\end{array}$ & $\begin{array}{c}\text { LOG(OUTPUT) } \\
\text { II }\end{array}$ & $\begin{array}{c}\text { LOG(OUTPUT) } \\
\text { III }\end{array}$ & $\begin{array}{c}\text { LOG(OUTPUT) } \\
\text { IV }\end{array}$ \\
\hline $\log _{-} C A P$ & $\begin{array}{c}0.037 * * * \\
(0.009)\end{array}$ & $\begin{array}{c}0.037 * * * * \\
(0.009)\end{array}$ & $\begin{array}{c}0.039 * * * \\
(0.009)\end{array}$ & $\begin{array}{c}0.037 * * * \\
(0.008)\end{array}$ \\
\hline $\log _{-} L A B$ & $\begin{array}{c}0.506^{* * * *} \\
(0.029)\end{array}$ & $\begin{array}{c}0.508^{* * * *} \\
(0.029)\end{array}$ & $\begin{array}{c}0.513 * * * \\
(0.029)\end{array}$ & $\begin{array}{c}0.527 * * * \\
(0.026)\end{array}$ \\
\hline $\log _{-} M A T$ & $\begin{array}{c}0.398^{* * * *} \\
(0.016)\end{array}$ & $\begin{array}{c}0.399 * * * * \\
(0.016)\end{array}$ & $\begin{array}{c}0.401 \cdots * * \\
(0.015)\end{array}$ & $\begin{array}{c}0.401 * * * \\
(0.015)\end{array}$ \\
\hline GREEN_ONLY & $\begin{array}{c}-1.766 * * * * \\
(0.539)\end{array}$ & $\begin{array}{c}-1.740 * * * * \\
(0.532)\end{array}$ & $\begin{array}{c}-1.309^{* * * *} \\
(0.392)\end{array}$ & $\begin{array}{c}-1.482 * * * \\
(0.431)\end{array}$ \\
\hline$O R G A \_O N L Y$ & $\begin{array}{c}0.975^{* * * *} \\
(0.287)\end{array}$ & $\begin{array}{c}0.954 * * * \\
(0.285)\end{array}$ & $\begin{array}{l}1.219 * * * \\
(0.388)\end{array}$ & $\begin{array}{c}0.759 \cdots * * \\
(0.263)\end{array}$ \\
\hline BOTH & $\begin{array}{c}0.670^{* * * *} \\
(0.211)\end{array}$ & $\begin{array}{c}0.665^{* * * *} \\
(0.209)\end{array}$ & $\begin{array}{c}0.741^{* \cdots * *} \\
(0.243)\end{array}$ & $\begin{array}{c}0.664^{* \cdots * *} \\
(0.222)\end{array}$ \\
\hline$R \& D \_I N T$ & $\begin{array}{l}1.811 \\
(2.108)\end{array}$ & $\begin{array}{l}1.815 \\
(2.084)\end{array}$ & $\begin{array}{l}3.168^{*} \\
(1.786)\end{array}$ & $\begin{array}{c}2.331 \\
(1.784)\end{array}$ \\
\hline PATSTOCK & & $\begin{array}{l}-0.000 \\
(0.000)\end{array}$ & $\begin{array}{l}-0.000 \\
(0.000)\end{array}$ & $\begin{array}{c}-0.000 \\
(0.000)\end{array}$ \\
\hline INNOVATOR & & & $\begin{array}{c}-0.273 * * * \\
(0.097)\end{array}$ & \\
\hline PC_INNO & & & & $\begin{array}{c}-0.224 * * * \\
(0.078)\end{array}$ \\
\hline$P D_{-} I N N O$ & & & & $\begin{array}{l}-0.031 \\
(0.045)\end{array}$ \\
\hline$H A R D C O M P$ & & & $\begin{array}{c}-0.003 \\
(0.031)\end{array}$ & $\begin{array}{l}-0.010 \\
(0.029)\end{array}$ \\
\hline$H H I$ & $\begin{array}{l}-0.000 \\
(0.000)\end{array}$ & $\begin{array}{l}-0.000 \\
(0.000)\end{array}$ & $\begin{array}{l}-0.000 \\
(0.000)\end{array}$ & $\begin{array}{l}-0.000 \\
(0.000)\end{array}$ \\
\hline$A G E$ & $\begin{array}{l}0.002^{* * * *} \\
(0.001)\end{array}$ & $\begin{array}{l}0.002^{* * * *} \\
(0.001)\end{array}$ & $\begin{array}{l}0.002^{* * * *} \\
(0.000)\end{array}$ & $\begin{array}{l}0.001^{* * * *} \\
(0.000)\end{array}$ \\
\hline$E A S T_{G} E R$ & $\begin{array}{c}-0.274 * * * \\
(0.038)\end{array}$ & $\begin{array}{l}-0.273 * * * \\
(0.037)\end{array}$ & $\begin{array}{c}-0.273 * * * \\
(0.037)\end{array}$ & $\begin{array}{c}-0.259 * * * \\
(0.034)\end{array}$ \\
\hline CONSTANT & $\begin{array}{l}-0.510 * * * * \\
(0.155)\end{array}$ & $\begin{array}{c}-0.514^{* * * *} \\
(0.154)\end{array}$ & $\begin{array}{l}-0.521^{* * * *} \\
(0.134)\end{array}$ & $\begin{array}{l}-0.547^{* * * *} \\
(0.131)\end{array}$ \\
\hline \multirow{3}{*}{$\begin{array}{l}\mathrm{R}^{2} \\
\text { Root MSE } \\
\text { Observations }\end{array}$} & 0.763 & 0.768 & 0.784 & 0.813 \\
\hline & 0.960 & 0.949 & 0.918 & 0.852 \\
\hline & 3,896 & 3,896 & 3,896 & 3,896 \\
\hline One-sided test against $\mathrm{H}_{0}$ : & \multicolumn{4}{|c|}{$G R E E N \_O N L Y+O R G A \_O N L Y-B O T H \geq 0$} \\
\hline P-Value & 0.020 & 0.010 & 0.025 & 0.002 \\
\hline \multicolumn{5}{|c|}{$\begin{array}{l}* \mathrm{p}<0.10, * * \mathrm{p}<0.05, * * * \mathrm{p}<0.01 \text {, robust standard errors appear in parentheses } \\
\dagger \text { The variables GREEN_ONLY,ORGA_ONLY, and BOTH are instrumented using the predicted probabilities } \\
\text { from the respective bivariate probit model specifications. The models include } 21 \text { jointly significant sector dummies } \\
\text { based on aggregated NACE } 2 \text {-digit levels. }\end{array}$} \\
\hline
\end{tabular}


However, as mentioned earlier to say that complementarity is present requires to test for validity of the condition of supermodularity stated in the inequality 12. Table 4 therefore provides results for a one-sided test against the null that GREEN_ONLY +ORGA_ONLY - BOTH $\geq 0$ which ought to be rejected if complementarity is present. As said, NEITHER is linearly dependent and serves as the reference category. The test statistics prsented at the bottom of Table 4 provide significant evidence for complementarity of green and organizational innovations in all model specifications.

\section{V.C Quality of the Constructed Instruments}

In the output regression presented above, the key independent variables are endogenous and instrumented using their predicted values from a bivariate profit estimation. If, however, these instruments are weak in the sense that they are only weakly correlated with the endogenous variables, the estimates of the complementary variables may be seriously biased. For this reason, we test the validity of these instruments.

Due to the use of three predicted values from the bivariate profit as instruments for the three innovation adoption decisions (the fourth one is linearly dependent), the model is by construction just identified. Moreover, with three endogenous variables and three instruments, it is not possible to obtain critical values for the two weak-identification tests suggested by Stock and Yogo (2005). We therefore stick to the rule of thumb offered by Staiger and Stock (1997). This rule is to look on the first stage F-statistics of joint significance of the instruments. A F-value of 10 or higher suggests the validity of the instruments. For all estimated model specifications, the first stage F-statistics are provided below in Table 5 and indicate non-weakness of the instruments.

Table 5: First Stage F-Statistics for the Excluded Instruments

\begin{tabular}{lcccc}
\hline \hline \multirow{2}{*}{ FIRST STAGE } & \multicolumn{4}{c}{ MODEL SPECIFICATIONS } \\
\cline { 2 - 5 } F-STATISTICS & $\mathbf{1}$ & $\mathbf{2}$ & $\mathbf{3}$ & $\mathbf{4}$ \\
\hline GREEN_ONLY & 15.4009 & 15.4876 & 20.4808 & 19.0512 \\
& $(0.0000)$ & $(0.0000)$ & $(0.0000)$ & $(0.0000)$ \\
ORGA_ONLY & 26.8120 & 26.5090 & 27.4216 & 31.6028 \\
& $(0.0000)$ & $(0.0000)$ & $(0.0000)$ & $(0.0000)$ \\
BOTH & 83.0185 & 82.7292 & 77.3350 & 66.9240 \\
& $(0.0000)$ & $(0.0000)$ & $(0.0000)$ & $(0.0000)$ \\
\hline
\end{tabular}

P-values for the F-test against the null that the instruments are not jointly statistically different from zero appear in parentheses. 


\section{Concluding Remarks}

The motivation for the presented analysis was drawn from two fields of research. First, the literature on within-firm organizational change and productivity suggests that firms can make more efficient use of certain technologies if complementary forms of organization are adopted. These cross-effects between technology and organizational structure may be crucial to explaining the "productivity paradox" related to the lacking productivity effects following the introduction of new technologies. Second, this aspect may be of even greater importance for the case of greenhouse gas (GHG) abatement technologies that are imposed by public authority and have the aim to reduce social costs of climate change. The private returns to the introduction of such technologies are apparently less obvious or can even expected to be negative. Previous research, however, had largely neglected the relationship between green technologies and organizational change. Our analysis of German firm-level data shows that indeed organizational change increases the returns to the use of $\mathrm{CO}_{2}$ reducing technologies which results in positive effects on productivity. Without having introduced adequate organizational infrastructure, such technology is associated with significantly lower productivity. The results from our two-stage estimation procedure thus suggest that the introduction of green technologies and organizational innovations are complementary. In other words, firms that adopted green technologies jointly with changes to their organizational structure can make better use of green technologies and hence more than offset productivity losses compared to firms having only adopted green technology.

A conclusion our results do not allow is that green technology adoption per se is beneficial to a firm if it also introduces the right organizational structure. Or in other words, our results do not allow to conclude that environmental policy should implement more stringent regulations as to promote technology adoption that, in the end, increases productivity if firms implement the right organizational structure. Such a naive view would neglect the possibility that a firm could have had adopted an even more productivity increasing technology, had there been no regulatory pressure to adopt green technology due to budget constraints. Such a crowding out effect is for instance documented in Gray and Shadbegian (1998). Future research may address these concerns in the debate of productivity or competitiveness effects of green technology. 


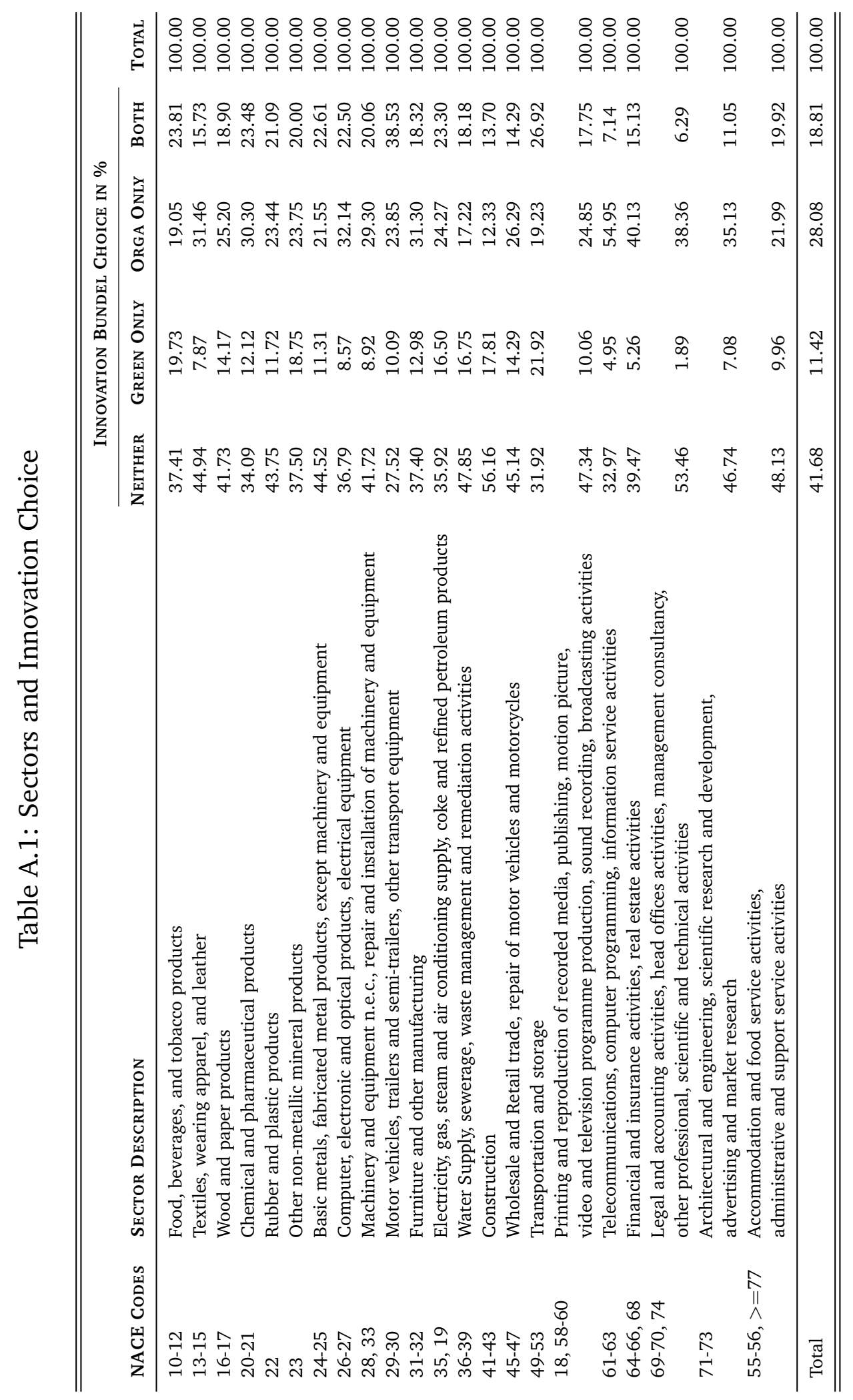




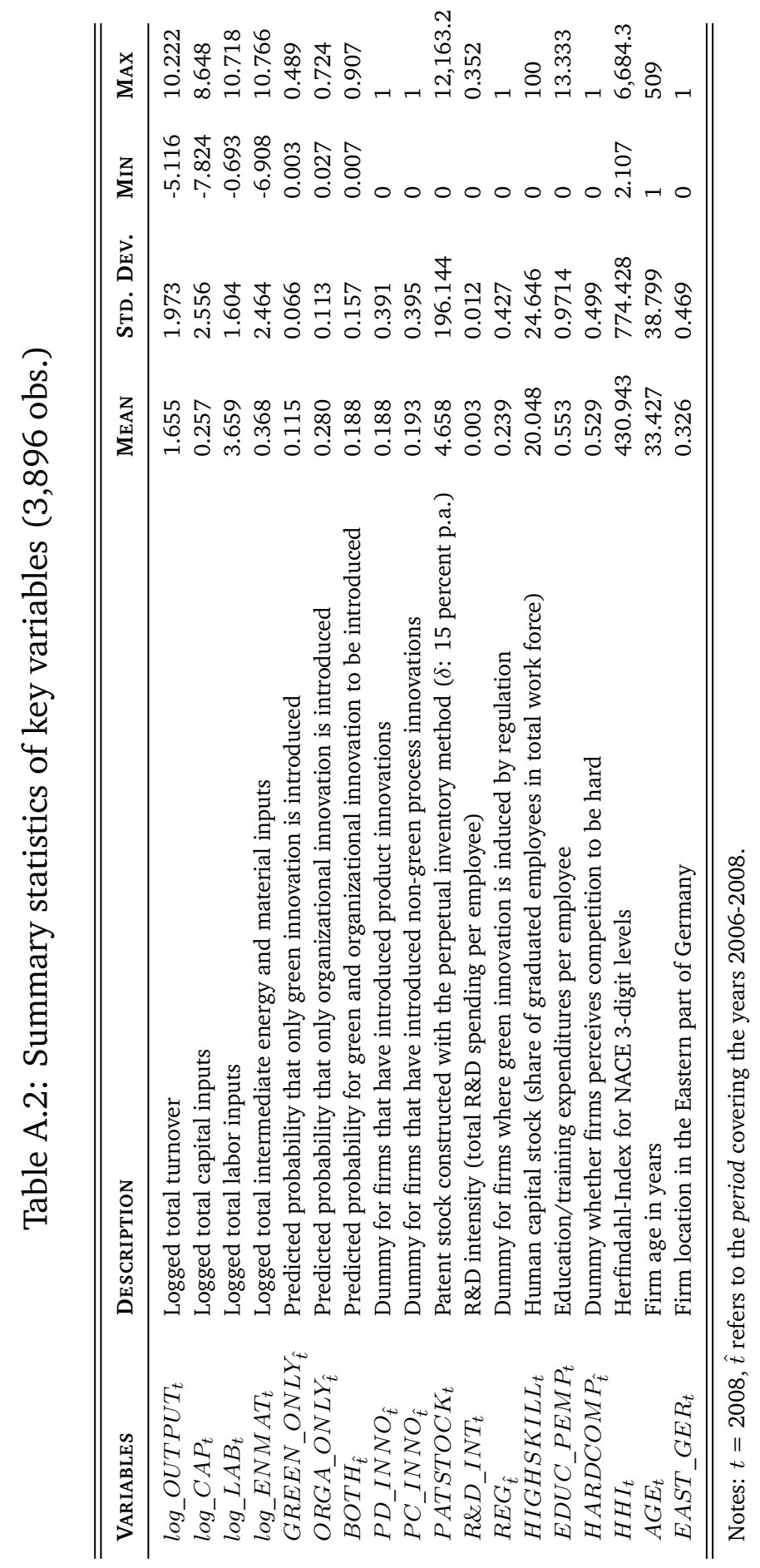




\section{REFERENCES}

Antonioli, D., S. Mancinelli, and M. Mazzanti (2011), Are Environmenmental Innovations Embedded within High-Performance Organizational Changes?, University of Ferrara Porking Paper October 2011(15).

Arora, A. (1996), Testing for Complementarities in Reduced-form Regressions: A note, Economics Letters 50(1), 51-55.

Arora, A., C. Forman, and J. W. Yoon (2010), Complementarity and Information Technology Adoption: Local Area Networks and the Internet, Information Economics and Policy 22(3), 228-242.

Arora, A. and A. Gambardella (1990), Complementarity and External Linkages: The Strategies of the Large Firms in Biotechnology, The Journal of Industrial Economics 38(4), 361-379.

Athey, S. and S. Stern (1998), An Empirical Framework for Testing Theories About Complementarity in Organizational Design, National Bureau of Economic Research, NBER Working Paper Series 6600.

Atkeson, A. and P. J. Kehoe (1999), Models of Energy Use: Putty-Putty versus Putty-Clay, The American Economic Review 89(4), 1028-1043.

Berman, E. and L. T. Bui (2001), Environmental Regulation and Productivity: Evidence from Oil Refineries, The Review of Economics and Statistics 83(3), 498-510.

Bloom, N., C. Genakos, R. Martin, and R. Sadun (2010), Modern Management: Good for the Environmenment or Just Hot Air?, The Economic Journal 120(544), 551-572.

Bloom, N., R. Sadun, and J. Van Reenen (2012), Americans Do I.T. Better: US Multinationals and the Productivity Miracle, The American Economic Review 102(1), 167-201.

Bloom, N. and J. Van Reenen (2002), Patents, Real Options and Firm Performance, Economic Journal 112(3), 97-116.

Boyd, G. A. and J. D. McClelland (1999), The Impact of Environmental Constraints on Productivity Improvement in Integrated Paper Plants, Journal of Environmental Economics and Management 38(2), 121-142.

Bresnahan, T. F., E. Brynjolfsson, and L. M. Hitt (2002), Information Technology, Workplace Organization, and the Demand for Skilled Labor: Firm-Level Evidence, The Quarterly Journal of Economics 117(1), 339-376. 
Caroli, E. and J. Van Reenen (2001), Skill-Biased Organizational Change? Evidence From A Panel of Britisch and French Establishements, The Quarterly Journal of Economics 116(4), 1449-1492.

Commins, N., S. Lyons, M. Schiffbauer, and R. S. Toll (2011), Climate Policy \& Corporate Behavior, The Energy Journal 32(4), 51-68.

Gentzkow, M. (2007), Valuing New Goods in a Model with Complementarity: Online Newspapers, The American Economic Review 97(3), 713-744.

Goldin, C. and L. F. Katz (1998), The Origins of Technology-Skill Complementarity, The Quarterly Journal of Economics 113(3), 693-732.

Gray, W. B. (1987), The Cost of Regulation: OSHA, EPA and the Productivity Slowdown, The American Economic Review 77(5), 998-1006.

Gray, W. B. and R. Shadbegian (1998), Environmental Regulation, Investment Timing, and Technology Choice, Journal of Industrial Economics 46(2), 235256.

Gray, W. B. and R. J. Shadbegian (2003), Plant vintage, technology, and environmental regulation, Journal of Environmental Economics and Management 46(3), 384-402.

Griliches, Z. and J. Mairesse (1984), R\&D, Patents and Productivity, Chap. Productivity and R\&D at the Firm Level, The University of Chicago Press, Chicago, 152-175.

Hausman, J. A. (1978), Specification Tests in Econometrics, Econometrica 46(6), 1251-1271.

Hausman, J. A. (1983), Specification and Estimation of Simulatneous Equation Models, Vol. 1, Chap. 7, North-Holland, Amsterdam, 391-448.

Holmstrom, B. and P. Milgrom (1994), The Firm as an Incentive System, The American Economic Review 84(4), 972-991.

Horbach, J. (2008), Determinants of Environmental Innovation-New Evidence from German Panel Data Sources, Research Policy 37(1), 163-173.

Ichniowski, C., K. Shaw, and G. Prennushi (1997), The Effects of Human Resource Management Practices on Productivity: A Study of Steel Finishing Lines, The American Economic Review 87(3), 291-313.

Jaffe, A. B., R. G. Newell, and R. N. Stavins (2002), Environmental Policy and Technological Change, Environmental and Resource Economics 22(1-2), 4169. 
Johnstone, N., I. Hascic, and D. Popp (2010), Renewable Energy Policies and Technological Innovation: Evidence Based on Patent Counts, Environmental \& Resource Economics 45(1), 133-155.

Kerr, S. and R. G. Newell (2003), Policy-Induced Technology Adoption: Evidence from the U.S. Lead Phasedown, The Journal of Industrial Economics 51(3), 317-343.

Kretschmer, T., E. J. Miravete, and J. Pernías (2012), Competitive Pressure and the Adoption of Complementary Innovations, The American Economic Review 102(4), 1540-1570.

Martin, R., M. Muûls, L. B. de Preux, and U. Wagner (2012), Anatomy of a Paradox: Management Practices, Organizational Structure and Energy Efficiency, Journal of Environmental Economics and Management 63(2), 208-223.

Milgrom, P. and J. Roberts (1990), The Economics of Modern Manufacturing: Technology, Strategy, and Organization, The American Economic Review 80(3), 511-528.

Miravete, E. J. and J. Pernías (2006), Innovation Complementarity and Scale Production, The Journal of Industrial Economics 54(1), 1-29.

Miravete, E. J. and J. Pernías (2010), Testing for Complementarity when Strategies are Dichotomous, Economics Letters 106(1), 28-31.

Mohnen, P. and L.-H. Röller (2005), Complementarity in Innovation Policy, European Economic Review 49(6), 1431-1450.

Popp, D., R. G. Newell, and A. B. Jaffe (2010), Energy, the Environment, and Technological Change, Chap. 21, in: Handbook of Economics of Innovation (Bronwyn H. Hall and Nathan Rosenberg, eds.), North-Holland, Amsterdam, 873-937.

Shadbegian, R. J. and W. B. Gray (2005), Pollution Abatement Expenditures and Plant-Level Productivity: A production function Approach, Ecological Economics 54(2-3), 196-208.

Snyder, L. D., N. H. Miller, and R. N. Stavins (2003), AssociationThe Effects of Environmental Regulation on Technology Diffusion: The Case of Chlorine Manufacturing, The American Economic Review 93(2 Papers and Proceedings), 431-435.

Solow, R. M. (1957), Technical Change and the Aggregate Production Function, The Review of Economics and Statistics 39(3), 312-320. 
Staiger, D. and J. Stock (1997), Instrumental Variables Regression with Weak Instruments, Econometrica 65(3), 557-586.

Stock, J. H. and M. Yogo (2005), Identification and Inference for Econometric Models: Essays in Honor of Thomas J. Rothenberg, Chap. Testing for Weak Instruments in Linear IV Regression, Cambridge University Press, chapter 5.

Syverson, C. (2011), What Determines Productivity?, Journal of Economic Literature 49(2), 326-365.

Wooldridge, J. M. (2002), Econometric Analysis of Cross Section and Panel Data. 